\title{
Synthesis and Characterization of Bisnitrofurazanofuroxan
}

\author{
Choong Hwan Lim, Tae Keun Kim, Kyung Ho Kim, Kyoo-Hyun Chung, and Jin Seuk Kim ${ }^{\dagger}$ \\ High Energy Material Research Center, Department of Chemistry, Inha University, Incheon 402-751, Korea \\ *E-mail:kyoohyun@inha.ac.kr \\ ${ }^{\dagger}$ Agency for Defense Development, Yuseong P.O. Box 35-5 (TRC-3-6), Daejeon 305-600, Korea \\ Received December 29, 2009, Accepted March 13, 2010
}

Key Words: Furazan, Furoxan, Cycloaddition, Oxidation, Energetic material

Although various explosives have been continuously prepared, higher performance and lower sensitivity have been a keen concern in weapon system. ${ }^{1}$ Since most compounds containing a furazan ring (1,2,5-oxadiazole, Figure 1) have high nitrogen content, high energy density, and good thermal stability, nitro and amino derivatives are energetic materials with potential use in both explosives and propellants. ${ }^{2}$ Some nitrosubstituted furazans have excellent oxygen balance and exhibit explosive performance close to those of highly powerful explosives, but they are often too sensitive. ${ }^{3}$

A furoxan (1,2,5-oxadiazole $N$-oxide, Figure 1) is also a highly energetic heterocycle whose introduction into organic compounds generally increases crystal density and improves explosive performance. ${ }^{4}$ In addition, many furoxan derivatives exhibit biological activities such as donors of nitrogen oxide. ${ }^{5}$

Simple furoxans containing nitro groups could not be applied for energetic materials because of their poor thermal stability and nucleophilic displacement of the nitro groups. On the other hand, benzofuroxans are far more stable than the furoxans and more favorable for practical applications. ${ }^{6}$ Since simple nitrofurazans or nitrofuroxans are unstable to be used as an explosive, other derivatives have been developed, such as 4,4'-dinitro-3,3'-diazinofurazan, 4,4'-dinitro-3,3'-diazinofuroxan, and

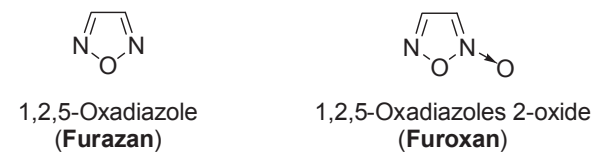

Figure 1. Structures of a furazan and a furoxan. their azoxy derivatives. ${ }^{4}$ Among them, 3,4-bis(3-nitrofurazan4-yl)furoxan (BNFF, 7) showed good performance. One synthetic method for BNFF is not practical, ${ }^{7}$ and the other is not disclosed in detail. ${ }^{8}$ In the present study, we have focused on developing nitrofurazans combined with a furoxan moiety that are expected to be thermally stable and less sensitive to impact. In this paper, we will study a synthetic method that can produce BNFF in large scale.

Since the method using $n$-BuLi was not practical, ${ }^{7}$ a more convenient method was designed as shown in Scheme 1. 3Amino-4-aminoximidofurazan (3) could be readily prepared from malononitrile, and the subsequent deamino-chlorination of 3 should afford 3-amino-4-chloroximidofurazan (4). Treatment of chloroxime 4 with a base followed by heating of the resulting nitrile oxide 5 would give 3,4-bis(aminofurazano) furoxan (BAFF, 6), and then 3,4-bis(nitrofurazano)furoxan (BNFF, 7) could be obtained by oxidation.

According to Scheme 1, malononitrile was treated with sodium nitrite in $\mathrm{HCl}$ to introduce an oxime moiety in the methylene position. ${ }^{9}$ Without isolation of resulting oxime $\mathbf{1}$, a reaction of 1 with hydroxyamine hydrochloride gave tri-oxime $\mathbf{2}$, which was converted to aminoximidofurazan $\mathbf{3}$ by heating to reflux under basic condition. During the process, the nitrile groups were converted to aminoximes and dehydration of the resulting tri-oxime took place to produce furazan 3 . Therefore, the key furazan intermediate $\mathbf{3}$ was obtained through one pot reaction starting from malononitrile. ${ }^{9 b}$

The initial deamino-chlorination of aminoxime $\mathbf{3}$ was done by the reaction with $\mathrm{NaNO}_{2}$ in $6 \mathrm{M} \mathrm{HCl}$ to provide chloroxime 4 in low yield. ${ }^{10}$ Under the various reaction conditions, the re-

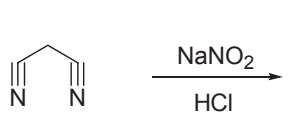

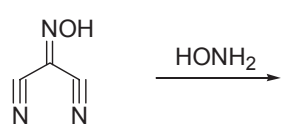

1<smiles>N=C(N)C(=N)C(N)=[NH+]O</smiles>

2

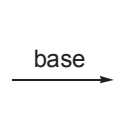<smiles>NC(=NO)c1nonc1N</smiles>

3

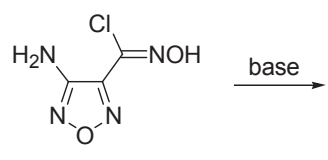

4

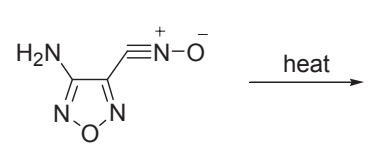

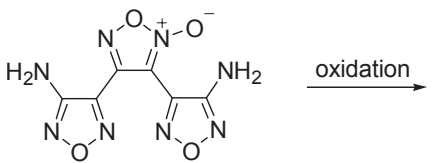

$\operatorname{BAFF}(6)$

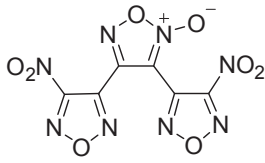

BNFF (7)

Scheme 1. Synthetic design of BNFF 


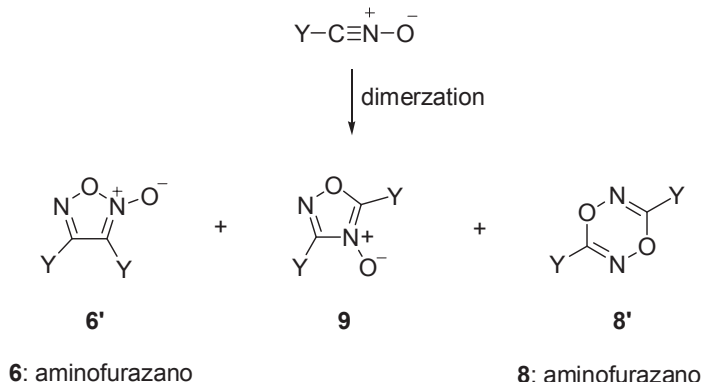

Scheme 2. Dimerzation of a nitrile oxide

action yield was not much improved. The best result was accomplished with addition of $\mathrm{CuCl}$, which is a typical process to provide a chloro compound from diazonium salt as in the Sandmeyer reaction.

The next step was to make nitrile oxide $\mathbf{5}$ which could be used as a precursor of BAFF. When chloroxime $\mathbf{4}$ was treated with base, nitrile oxide $\mathbf{5}$ was not isolated, but dimerization reactions took place to afford ring compounds. In the previous reports, the dimerization of nitrile oxide 5 produced a mixture of BAFF and 3,6-bis(4-amino-1,2,5-oxadiazol-3-yl)-1,4,2,5,dioxadiazine (8). Treatment with aq. $\mathrm{Na}_{2} \mathrm{CO}_{3}$ in $\mathrm{Et}_{2} \mathrm{O}$ gave mainly 5-membered BAFF, while triethylamine in acetonitrile afforded the 6-membered 1,4,2,5-dioxadiazine (8), one of isomers of BAFF (Scheme 2). ${ }^{11}$ The latter result was different from the general observation to some extent. ${ }^{12}$

The dimerization of nitrile oxides was known to produce two 5-membered and one 6-membered ring compounds. Between 5-membered structures, formation of 1,2,5-oxadiazole-2-oxide (6', a furoxan) was kinetically more favorable than that of 1,2,4oxadiazole-4-oxide (9), but not thermodynamically, on the basis of molecular orbital calculations. ${ }^{13}$

We have focused on this reaction, because there was no explanation on the reaction conditions to produce one of the isomers as a major compound. We varied reaction conditions such as solvent, temperature, base and amount of base (Table 1). Sodium carbonate gave better result than sodium hydroxide (entries 1 and 2). The reaction results were almost the same regardless of the matals of carbonates (entries 2 and 3 ). When the reactions took place with more equivalents of base or at higher temperature, a portion of the unknown compound increased (entries 4 and 5). When the reaction was carried out in ether, ethyl acetate, or methylene chloride, BAFF was major (entries 3, 6, and 7). On the other hand, the reaction in THF, acetonitrile or methanol afforded 1,4,2,5-dioxadiazine 8 as a major product (entries 8, 9, and 10).

Depending upon the phase of the reaction mixture, the major product might be changed. In other word, BAFF was major in heterogeneous conditions, whereas isomer $\mathbf{8}$ was in homogeneous ones. Since the isomer was almost insoluble in any solvent, it seemed to precipitate out of the equilibrium, and then the reaction proceeded to give $\mathbf{8}$ as a major compound.

Depending on the bases, a ratio of the isomeric products was considerably different. Metal carbonates favored BAFF, while triethylamine did dioxadiazine 8. However, ammonium hydroxide yielded only the unknown mixture containing aminoxime
Table 1. Dimerization of nitrile oxide 5

\begin{tabular}{|c|c|c|c|c|c|c|c|}
\hline \multirow{2}{*}{ Entry } & \multirow{2}{*}{ Solvent } & \multirow{2}{*}{$\begin{array}{l}\text { Temp. } \\
\left({ }^{\circ} \mathrm{C}\right)\end{array}$} & \multirow{2}{*}{ Base } & \multirow{2}{*}{$\begin{array}{c}\text { Base } \\
\text { (mole equiv) }\end{array}$} & \multicolumn{3}{|c|}{ Product $^{a}$} \\
\hline & & & & & 6 & 8 & Unknown \\
\hline 1 & Ether & 0 & $\mathrm{NaOH}$ & 1.1 & 40 & 5 & 10 \\
\hline 2 & Ether & 0 & $\mathrm{Na}_{2} \mathrm{CO}_{3}$ & 0.5 & 67 & 5 & 5 \\
\hline 3 & Ether & 0 & $\mathrm{~K}_{2} \mathrm{CO}_{3}$ & 0.5 & 70 & 5 & 5 \\
\hline 4 & Ether & 0 & $\mathrm{~K}_{2} \mathrm{CO}_{3}$ & 1.1 & 45 & 5 & 20 \\
\hline 5 & Ether & 20 & $\mathrm{~K}_{2} \mathrm{CO}_{3}$ & 0.5 & 40 & 5 & 15 \\
\hline 6 & EA & 0 & $\mathrm{~K}_{2} \mathrm{CO}_{3}$ & 0.5 & 60 & 5 & 5 \\
\hline 7 & $\mathrm{MC}$ & 0 & $\mathrm{~K}_{2} \mathrm{CO}_{3}$ & 0.5 & 60 & 5 & 5 \\
\hline 8 & THF & 0 & $\mathrm{~K}_{2} \mathrm{CO}_{3}$ & 0.5 & 3 & 70 & - \\
\hline 9 & $\mathrm{MeCN}$ & 0 & $\mathrm{~K}_{2} \mathrm{CO}_{3}$ & 0.5 & 2 & 65 & - \\
\hline 10 & $\mathrm{MeOH}$ & 0 & $\mathrm{~K}_{2} \mathrm{CO}_{3}$ & 0.5 & 3 & 67 & - \\
\hline 11 & Ether & 0 & TEA & 1.1 & 3 & 50 & 15 \\
\hline 12 & $\mathrm{CH}_{3} \mathrm{CN}$ & 0 & TEA & 1.1 & 2 & 65 & - \\
\hline $13^{b}$ & Ether & 0 & $\mathrm{NH}_{4} \mathrm{OH}$ & 1.1 & - & - & 65 \\
\hline
\end{tabular}

${ }^{a}$ Isolated yield. ${ }^{b}$ The unknown mixture contained some of $\mathbf{3}$.

3 (entries 2, 11, and 13). Under these conditions, the 1,2,4-oxadiazole-4-oxide isomer $(\mathbf{9}, \mathrm{Y}=$ aminofurazano) was not obtained as a major compound.

In the presence of alkene dipolarophiles such as styrene and ethyl acrylate, 1,3-dipolar cycloadditions with the intermediate 5 took place predominantly over the dimerization reactions of 5. ${ }^{1,14}$ Therefore the reaction rate of the dimerization seemed to be much slower than the 1,3-dipolar cycloadditions. Under this reaction condition, BAFF or dioxadiazine 8 was stable even in the presence of alkenes, indicating that the reversible reaction between 5 and 6 or 8 did not occur. ${ }^{15}$

The oxidation of animo groups attached to furazans gave various functional groups, such as nitro, diazo, azoxy, and their mixture, depending on the reaction conditions. The oxidation usually employs a combined mixture of hydrogen peroxide, an oxidizing agent such as sodium tungstate and ammonium persulfate, and a strong acid. ${ }^{3,16}$ In the previous report, the oxidation of BAFF with $96 \% \mathrm{H}_{2} \mathrm{O}_{2}$ and TFAA gave BNFF in $50 \%$ yield. $^{7}$ Other oxidation conditions were filed in the Chinese patents. $^{8,17}$

BAFF was hardly converted into BNFF in the reaction with $30 \% \mathrm{H}_{2} \mathrm{O}_{2}$ and $\mathrm{H}_{2} \mathrm{SO}_{4}$ in the presence of various additional oxidants. The reaction with $60 \% \mathrm{H}_{2} \mathrm{O}_{2}$ in TFAA proceeded to give $\mathrm{BNFF}$ in moderate yield. From the limited thermal data such as DSC and TGA, BNFF may be used as melt castable explosives like TNT. ${ }^{8,17}$

In summary, chloroxime 4, the precursor of the dimerized products was readily prepared in the presence of $\mathrm{CuCl}$ as in typical Sandmeyer reactions. BAFF, the key precursor of BNFF was produced as a major product in the reaction with about 0.5 mole equivalent of carbonate base in less polar solvent at rather lower temperature. The oxidation reaction conditions for practical applications will be studied further in our lab.

\section{Experimental Section}

General. ${ }^{1} \mathrm{H} /{ }^{13} \mathrm{C}$ NMR spectra were recorded on Varian Oxford 200 or Unityinova 400 instruments. Melting points were 
performed on recrystallized solids and recorded on a SRS OptiMelt or electrothermal 9100 melting point apparatus and were uncorrected.

Caution: Furazan and furoxan derivatives are suspected explosive. In addition to these compounds, $\mathrm{H}_{2} \mathrm{O}_{2}-\mathrm{H}_{2} \mathrm{SO}_{4}$ should be treated with appropriate precautions.

3-Amino-4-aminoximidofurazan (3). To a solution of malononitrile $(20 \mathrm{~g}, 0.3 \mathrm{~mol})$ in $2 \mathrm{~N} \mathrm{HCl}(300 \mathrm{~mL})$ was added dropwise a solution of $\mathrm{NaNO}_{2}(42 \mathrm{~g}, 0.6 \mathrm{~mol})$ in water $(80 \mathrm{~mL})$. After stirring for $12 \mathrm{~h}$ at $\mathrm{rt}$, and a solution of $\mathrm{NH}_{2} \mathrm{OH} \cdot \mathrm{HCl}(46 \mathrm{~g}$, $0.68 \mathrm{~mol})$ in water $(80 \mathrm{~mL})$ was added at $0{ }^{\circ} \mathrm{C}$. The mixture was adjusted to $\mathrm{pH} 10$ with aq. $\mathrm{NaOH}$ and the resulting solution was heated for $2 \mathrm{~h}$ at $35^{\circ} \mathrm{C}$, and heated to reflux for additional $2 \mathrm{~h}$. The resulting mixture was cooled to $0{ }^{\circ} \mathrm{C}$, and small amount of ethyl acetate was added to furnish the product as a white solid (35.5 g, 82\%). mp 192 $193{ }^{\circ} \mathrm{C}$ (ethyl acetate) ${ }^{1} \mathrm{H}$ NMR (DMSO- $\left.d_{6}, 400 \mathrm{MHz}\right) \delta 10.5(\mathrm{~s}, 1 \mathrm{H}), 6.26(\mathrm{~s}, 2 \mathrm{H}), 6.16$ (s, 2H); ${ }^{13} \mathrm{C}$ NMR (DMSO- $\left.d_{6}, 100 \mathrm{MHz}\right) \delta 154.5,144.0,140.1$.

3-Amino-4-chloroximidofurazan (4). To a suspension of $\mathbf{1}$ (20 g $0.14 \mathrm{~mol})$ in $\mathrm{MeOH}(200 \mathrm{~mL})$ was added conc. $\mathrm{HCl}$ (134 $\mathrm{mL})$, cuprous chloride $(14.3 \mathrm{~g}, 0.14 \mathrm{~mol})$, and a solution of $\mathrm{NaNO}_{2}(22.2 \mathrm{~g}, 0.32 \mathrm{~mol})$ in water $(60 \mathrm{~mL})$ at $0{ }^{\circ} \mathrm{C}$. The reaction mixture was standing for $3 \mathrm{~h}$ at $0 \sim 5{ }^{\circ} \mathrm{C}$, and filtered. The solid was washed with cold water twice, and dried in vacuo to give an ivory solid (13.3 g, 59\%). The additional product could be obtained from the mother liquid. mp $203 \sim 206{ }^{\circ} \mathrm{C}$ (ether-pet. ether, dec.); ${ }^{1} \mathrm{H}$ NMR (DMSO- $\left.d_{6}, 400 \mathrm{MHz}\right) \delta 6.23$ (bs) $;{ }^{13} \mathrm{C}$ NMR (DMSO-d, $\left.100 \mathrm{MHz}\right) \delta 154.0,141.9,126.5$.

3,4-Bis(aminofurazano)furoxan (BAFF, 6). To a solution of $4(4.8 \mathrm{~g}, 0.03 \mathrm{~mol})$ in $\mathrm{Et}_{2} \mathrm{O}(60 \mathrm{~mL})$ was added dropwise $\mathrm{K}_{2} \mathrm{CO}_{3}$ $(2.35 \mathrm{~g}, 0.017 \mathrm{~mol})$ in water $(60 \mathrm{~mL})$ for $30 \mathrm{~min}$. After stirring for $2 \mathrm{~h}$ at $10^{\circ} \mathrm{C}$, the solid was filtered, and the resulting mother liquid was extracted with ethyl acetate three times. The organic layer was dried over $\mathrm{MgSO}_{4}$, and concentrated in vacuo to give a crude product as a pale yellow solid. The crude product was purified by recrystallization from ethyl acetate/hexane to give a white solid (2.61 g, 70\%). mp $165 \sim 170{ }^{\circ} \mathrm{C}($ dec. $) ;{ }^{11 \mathrm{a}}{ }^{1} \mathrm{H}$ NMR (DMSO- $\left.d_{6}, 400 \mathrm{MHz}\right) \delta 6.63(\mathrm{~s}, 2 \mathrm{H}), 6.58(\mathrm{~s}, 2 \mathrm{H}) ;{ }^{13} \mathrm{C} \mathrm{NMR}$ (DMSO- $\left.d_{6}, 100 \mathrm{MHz}\right) \delta 156.0,155.1,146.5,136.2,133.3,104.2$.

3,4-Bis(nitrofurazano)furoxan (BNFF, 7). To a solution of $60 \% \mathrm{H}_{2} \mathrm{O}_{2}(3.3 \mathrm{~mL}, 0.07 \mathrm{~mol})$ in methylene chloride $(26 \mathrm{~mL})$ was added slowly trifluoroacetic anhydride $(7.4 \mathrm{~mL}, 0.05 \mathrm{~mol})$ maintaining below $5{ }^{\circ} \mathrm{C}$, and $\mathbf{6}(1.0 \mathrm{~g}, 4.0 \mathrm{mmol})$ was added in a small portion. The mixture was stirred at room temperature for $1 \mathrm{~h}$, and heated to reflux for $3 \mathrm{~h}$. The reaction mixture was washed with $\mathrm{H}_{2} \mathrm{O}$ twice and then with $10 \% \mathrm{NaHCO}_{3}$ twice. The organic layer was dried over $\mathrm{MgSO}_{4}$, filtered and concentrated under reduced pressure. The residue was purified by flash silica gel chromatography $(\mathrm{MC}: \mathrm{Hex} .=1: 1)$ to give a white solid $(0.63 \mathrm{~g}, 51 \%)$. mp $108 \sim 110{ }^{\circ} \mathrm{C}($ dec. $) ;{ }^{713} \mathrm{C}$ NMR (DMSO- $d_{6}$, $100 \mathrm{MHz}) \delta 160.2$, 160.0, 143.0, 139.5, 137.0, 103.5.

3,6-Bis(4-amino-1,2,5-oxadiazol-3-yl)-1,4,2,5,-dioxadiazine (8). To a solution of $4(0.33 \mathrm{~g}, 2 \mathrm{mmol})$ in THF $(10 \mathrm{~mL})$ was added dropwise a solution of $\mathrm{K}_{2} \mathrm{CO}_{3}(0.15 \mathrm{~g})$ in water $(10 \mathrm{~mL})$ for $30 \mathrm{~min}$. The reaction mixture was standing for $2 \mathrm{~h}$ below $10{ }^{\circ} \mathrm{C}$, and filtered to give a with solid $(0.175 \mathrm{~g}, 70 \%)$. mp $230 \sim$
$233{ }^{\circ} \mathrm{C}$ (dec.); ${ }^{11 \mathrm{c}}{ }^{1} \mathrm{H}$ NMR (DMSO- $\left.d_{6}, 400 \mathrm{MHz}\right) \delta 6.54$ (bs);

${ }^{13} \mathrm{C}$ NMR (DMSO- $\left.d_{6}, 100 \mathrm{MHz}\right) \delta 155.0,153.5,136.0$.

Acknowledgments. This work was supported by the Korean Agency for Defense Development.

\section{References}

1. (a) Lim, C. H.; Hong, S.; Chung, K.-H.; Kim, J. S.; Cho, J. R. Bull. Korean Chem. Soc. 2008, 29, 1415. (b) Katrizky, A. R.; Sommen, G. L.; Gromova, A. V.; Witek, R. M.; Steel, P. J.; Damavarapu, R. Chem. Heterocycl. Comp. 2005, 41, 111. (c) Latypov, N. V.; Bergman, J.; Langlet, A.; Wellmar, U.; Bemm, U. Tetrahedron 1998, 54,11525 .

2. Coburn, M. D. J. Heterocycl. Chem. 1968, 5, 83.

3. Aleksandrova, N. S.; Kharitonova, O. V.; Khmelnitskii, L. I.; Kulagina, V. O.; Melnikova, T. M.; Novikov, S. S.; Novikova, T. S.; Pivina, T. S.; Sheremetev, A. B. Mendeleev Commun. 1994, 230.

4. Agrawal, J. P.; Hodgson, R. D. Organic Chemistry of Explosives; John Wiley \& Sons: West Sussex, England, 2007; p 302.

5. (a) Bohn, H.; Brendel, J.; Martorana, P. A.; Schonafinger, K. Brit. J. Pharm. 1995, 114, 1605. (b) Gasco, A.; Fruttero, R.; Sorba, G. IL Pharmaco 1996, 51, 617. (c) Cerecetto, H.; Di Maio, R.; Gonzalez, M.; Risso, M.; Saenz, P.; Seoane, G.; Denicola, A.; Peluffo, G.; Quijano, C.; OleaAzar, C. J. Med. Chem. 1999, 42, 1941. (d) Boschi, D.; Cena, C.; Di Stilo, A.; Fruttero, R.; Gasco, A. Bioorg. Med. Chem. 2000, 8, 1727. (e) Li, M.; Sishen, F.; Mei, L. G. Chem. Pharm. Bull. 2000, 48, 808.

6. (a) Norris, W. P.; Spear, R. J. Propell. Explos. Pyrotech. 1983, 8 , 85. (b) Agrawal, J. P.; Mehilal, R. B. S.; Shinde, P. D. Propell. Explos. Pyrotech. 2003, 28, 77.

7. Sheremetev, A. B.; Ivanova, E. A.; Spiridonova, N. P.; Tselinsky, I. V.; Suponitsky, K. Y.; Antipin, M. J. Heterocycl. Chem. 2005, $42,1237$.

8. Zhao, F.-Q.; Chen, P.; Hu, R.-Z.; Luo, Y.; Zhang, Z.-Z.; Zhou, Y.-S.; Yang, X.-W.; Gao, Y.; Gao, S.-L.; Shi, Q.-Z. J. Hazardous Materials A 2004, 113, 67.

9. (a) Ichikawa, T.; Kato, T.; Takenishi, T. J. Heterocycl. Chem. 1965, 2, 253. (b) Beaudegnies, R.; Wendeborn, S. Heterocycles 2003, 60, 2417.

10. Andranov, V.; Eremeev, A. Khimiya Geterotsiklicheskikh Soedinenii 1994, 3, 420. CAN 123:198702.

11. (a) Tselinskii, I. V.; Mel'nikova, S. F.; Romanova, T. V.; Spiridonova, N. P.; Dundukova, E. A. Russ. J. Org. Chem. 2001, 37, 1355. (b) Wang, J.; Li, J.; Liang, Q.; Huang, Y.; Dong, H. Propel. Explos. Pyrotech. 2008, 33, 347. (c) Wang, J.; Dong, H.-S.; Huang, Y.-G.; Zhou, X.-Q.; Li, J.-S. Chin. J. Synth. Chem. 2006, 14, 131. CAN $145 ; 251737$.

12. Lee, S. H.; Jo, I.; Lee, J. H.; Hwang, K.-J. Bull. Korean Chem. Soc. 1997, 18, 1115.

13. Yu, Z.-X.; Caramella, P.; Houk, K. N. J. Am. Chem. Soc. 2003, 125, 15240.

14. Matt, C.; Gissot, A.; Wagner, A.; Mioskowski, C. Tetrahedron Lett. 2000, 41, 1191.

15. Kim, G. Y.; Kim, J.; Lee, J. H.; Kim, H. J.; Hwang, K-J. Bull. Korean Chem. Soc. 2009, 30, 459.

16. (a) Boldyrev, M. D.; Gidaspov, B. V.; Nikolaev, V. D.; Soludyuk, G. D. J. Org. Chem. (USSR) 1981, 17, 756. (b) Lee, G. S.; Mitchell, A. R.; Pagoria, P. F.; Schmidt, R. D. J. Heterocycl. Chem. 2001, $38,1227$.

17. Zhao, F.-Q.; Guo, P.-J.; Hu, R.-Z.; Zhang, H.; Xia, Z.-M.; Gao, H.-X.; Chen, P.; Luo, Y.; Zhang, Z. Z.; Zhuo, Y.-S.; Zhau, H.-A.; Gao, S.-L.; Shi, Q.-Z.; Lu, G.-E.; Jiang, J.-Y. Chin. J. Chem. 2006, 24,631 . 